\title{
A ATUAÇÃO DOS CONSÓRCIOS DE EXPORTAÇÃO BRASILEIROS EM RELAÇÃO À COOPERAÇẨO, AQUISIÇÃO DE INOVAÇÕES E PERFORMANCE EXPORTADORA
}

\author{
THE PERFORMANCE OF EXPORT CONSORTIA \\ BRAZILIAN REGARDING COOPERATION, THE \\ ACQUISITION OF INNOVATIONS AND \\ EXPORT PERFORMANCE
}

\author{
Recebido 19/08/2012 \\ Aceito $20 / 08 / 2012$ \\ Aletéia de Moura Carpes ${ }^{1}$, Flavia Luciane Scherer ${ }^{2}$, Thiago Antonio Beuron ${ }^{3}$ \\ Maríndia Brachak dos Santos ${ }^{4}$, Diego Echevengua Borges ${ }^{5}$, Bruno de Moura Carvalho ${ }^{6}$
}

\section{RESUMO}

Este estudo objetiva analisar a atuação dos consórcios de exportação brasileiros quanto à cooperação, facilitação para adquirir inovações e desempenho exportador dos membros, por meio de pesquisa realizada com empresas de diferentes consórcios e setores da economia. Fazendo uso de pesquisa survey e análise via estatística descritiva e Correlação de Pearson, sobressaíram-se que as firmas buscam se adequar aos padrões internacionais de tecnologia, no entanto foi o esforço individual da empresa o maior responsável pelas inovações adquiridas, estando o desempenho exportador de grande parte aquém do desejado. Atividades conjuntas deveriam ser mais exploradas, enfatizando ações que visam a retornos de longo prazo, espelhando-se no sucesso de modelos internacionais de consórcios de exportação.

Palavras-chave: Consórcio de Exportação; Cooperação; Inovações; Performance Exportadora

\footnotetext{
${ }^{1}$ UFSM - Universidade Federal de Santa Maria. E-mail: alecarpes.adm@ @otmail.com

${ }^{2}$ UFSM - Universidade Federal de Santa Maria. E-mail: flaviascherer@globo.com

${ }^{3}$ UNIPAMPA - Universidade Federal do Pampa. E-mail: tbeuron@hotmail.com

${ }^{4}$ UFSM - Universidade Federal de Santa Maria. E-mail: marindiabrachak@hotmail.com

${ }^{5}$ UFSM - Universidade Federal de Santa Maria. E-mail: diego.e.borges@hotmail.com

${ }^{6}$ EEAr - Escola de Especialistas da Aeronáutica. E-mail: mc.brunocarv@pop.com.br
} 


\section{ABSTRACT}

This study aims to analyze the performance of export consortia as Brazilian cooperation, facilitation to acquire innovation and export performance of the members through research consortia with different companies and sectors of the economy. Making use of survey research and analysis by descriptive statistics and Pearson Correlation, highlights that firms seek to conform to international standards of technology, however, was the individual effort of the company responsible for the biggest innovations acquired while the export performance of much below the desired level. Joint activities should be further explored, emphasizing actions aimed at long-term, reflecting on the success of international models of export consortia.

Keywords: Export Consortia; Cooperation; Innovation; Export Performance

\section{INTRODUÇÃO}

O comércio de bens entre os países é estimulado desde a época do mercantilismo, quando os pagamentos às exportações eram realizados com ouro e prata, e a acumulação destes constituía a riqueza e o poder de uma nação. No entanto, foi a partir das últimas décadas do século XX que o comércio internacional foi visto como evidente e fundamental para a economia, que de mundial passou a global (CASTELLS, 1999), com o ingresso de um grande número de novos atores que quebravam o paradigma da hegemonia bipolar no mundo.

As firmas que optam pela internacionalização buscam encontrar a variedade de

benefícios advindos da atividade com o exterior, relacionadas a uma satisfatória performance exportadora, que é caracterizada pelo desempenho/atuação no mercado internacional. De acordo com Machado (2005), muitos estudos apontam o fato de que a performance e o sucesso obtidos na atividade de exportação são fatores condicionantes para a alavancagem da empresa no envolvimento exportador.

Diante do contexto da atividade global que envolve comércio internacional e percebendo a internacionalização como um processo estratégico, torna-se fundamental que as empresas agreguem, em suas atividades, práticas de inovação, sendo estas definidas por Bessant e Tidd (2009, p. 22) como a "habilidade de fazer relações, visualizar oportunidades e de tirar vantagens das mesmas". Os autores associam inovação ao crescimento empresarial e afirmam que as empresas que não inovam correm o risco de serem superadas por outras que o façam, sendo, então, uma questão de sobrevivência a qualquer firma.

Visando à exploração dos benefícios advindos da internacionalização, muitas empresas têm buscado a inovação administrativa (formação das redes de cooperação) para facilitar a inovação tecnológica em seus produtos e atingirem a performance exportadora desejada, constituindo redes de cooperação empresarial na forma de consórcios de exportação. Os consórcios de exportação funcionam como uma associação de empresas juridicamente constituídas, que conjugam esforços e estabelecem uma divisão interna de trabalho, com vistas à redução de custos, ao aumento da oferta de produtos e à ampliação das exportações (BRANCO e MACHADO, 2004).

Porter (1989, p. 75) defende que "um ato de inovação estratégica libera, com frequência, o potencial de globalização", ou seja, as firmas que, de alguma maneira, inovam tornam-se mais aptas à integração em termos de bens e serviços, caracterizada como a globalização dos mercados. Partindo-se dessas considerações, a seguir, será verificada a atuação dos consórcios de exportação brasileiros como rede de cooperação e meio para adquirir inovações tecnológicas e performance exportadora satisfatória. 
A partir da apreciação da literatura referente ao tema, foram elaboradas três hipóteses a serem refutadas ou corroboradas após as análises dos dados empíricos: "empresas que integram algum consórcio de exportação têm performance exportadora satisfatória"; "empresas que inovam tecnologicamente têm performance satisfatória"; e "o consórcio de exportação, como inovação administrativa, viabiliza a aquisição de inovações tecnológicas às empresas". Para analisar a validade das hipóteses no contexto brasileiro dos consórcios de exportação, utilizou-se a estatística descritiva e o coeficiente de Correlação de Pearson a fim de verificar a associação entre cooperação na rede, aquisição de inovações e performance exportadora.

\section{CONSIDERAÇÕES ACERCA DOS CONSÓRCIOS DE EX- PORTAÇÃO}

Os consórcios de exportação, criados no Brasil nos anos 1970 (PORTO, 2006, p. 41) e expandidos no país no final da década de 1990, podem ser considerados uma estratégia a ser utilizada pelas micro e pequenas empresas no auxílio à exploração de novos horizontes da arena global, servindo como meio para a internacionalização e forma de fortalecer as empresas de micro, pequeno e médio porte em grande parte de seus pontos considerados frágeis. Para Maciel e Lima (2002), qualquer união de empresas visando à internacionalização pode ser considerada um consórcio de exportação.

Os consórcios de exportação funcionam como uma associação de empresas juridicamente constituídas, que conjugam esforços e estabelecem uma divisão interna de trabalho, com vistas à redução de custos, ao aumento da oferta de produtos e à ampliação das exportações (BRANCO; MACHADO, 2004), funcionando, no Brasil, com auxílio da Agência de Promoção à Exportação e Investimentos- APEX BRASIL. Marques (2002) caracteriza um consórcio como uma associação temporária de várias empresas na qual juntam sinergia, aumentando a competitividade com a consequente redução de custos e riscos.

Casarotto Filho e Pires (2001) destacam que os consórcios são mecanismos essenciais à competitividade global e têm sido de extrema importância na aquisição de vantagens competitivas para as micro, pequenas e médias empresas no processo de internacionalização. Porto (2006, p.40) verifica que "os serviços oferecidos nesta modalidade convergem para a expansão conjunta de oportunidades aos seus membros no mercado internacional, seja pela inserção de empresas iniciantes ou pela consolidação de uma presença já conquistada". Da mesma forma, Casarotto Filho e Pires (2001) enfatizam que um consórcio deve distribuir regularmente informações genéricas às empresas, que permitam respostas rápidas por parte destas e concentração de esforços em projetos, em relação a oportunidades identificadas.

Com base no exposto, foi definida a primeira hipótese da pesquisa:

$\ulcorner----$ HIPÓTESE I (H.1): empresas que integram algum consórcio de exportação ----7

1 HIPOTESE I (H.1): empresas que integram algum consórcio de exportação

ᄂ _ _ _ _ _ _ _ _ têm performance exportadora satisfatória.

\section{A INOVAÇÃO NAS EMPRESAS}

O ingresso de diferentes atores no comércio internacional faz emergir a necessidade de obtenção de estratégias competitivas às firmas, que precisam ser flexíveis e inovadoras para superarem os concorrentes e obterem a preferência de uma demanda global, caracterizada pela avidez às novidades (CHURCHILL JR. e PETER, 2000). O esforço inovador é sempre recompensado, 
mas é muito mais difícil em países nos quais a infraestrutura de pesquisa, em universidades, institutos e nas próprias empresas, é mais modesta (STAL, 2010).

Arbix (2005) aponta que a competitividade, originada pela globalização mundial e abertura da economia a partir da década de 1990, fez com que surgisse uma nova visão empresarial, envolvida com as seguintes questões:

- Estratégias voltadas para a inovação e diferenciação do produto;

- Mudanças estruturais e organizacionais;

- Adequação das firmas aos padrões internacionais via inovação tecnológica;

- Inovação melhora o desempenho exportador das firmas;

- Internacionalização das firmas com foco na inovação tecnológica.

Bessant e Tidd (2009) lembram que "inovar" significa fazer algo novo, alterar. Como os mercados internacionais são caracterizados por uma maior pressão competitiva em relação ao mercado nacional, a inovação parece ser inevitável para sobrevivência das empresas (FILIPESCU, 2007), sendo que, se a atividade não envolver características inovadoras em produto, processo ou gestão, a concorrência a qual a empresa estará sujeita no mercado pode comprometer a sua performance e a lucratividade do negócio (ARBIX, 2005).

Damanpour (1991) divide a inovação nas seguintes ramificações: tecnológica e administrativa; de produto e de processo; radical e incremental. De acordo com o Manual de Oslo (2005), a inovação tecnológica é caracterizada por Inovação TPP, referente à Inovação Tecnológica em Produtos e Processos, classificada como

implantaçães de produtos e processos tecnologicamente novos e substanciais melhorias
tecnológicas em produtos e processos. Uma inovação TPP é considerada implantada se
tiver sido introduzida no mercado (inovação de produto) ou usada no processo de produção
(inovação de processo). Uma inovação TPP envolve uma série de atividades científicas,
tecnológicas, organizacionais, financeiras e comerciais. Uma empresa inovadora em TPP é
uma empresa que tenha implantado produtos ou processos tecnologicamente novos ou
com substancial melhoria tecnológica durante o período em análise (OCDE, 2005).

Arbix (2005) verifica que a inovação, particularmente tecnológica, é um dos motores fundamentais da competição e do desenvolvimento industrial. À medida que a empresa inova em seus processos e produtos, é possível aumentar a produtividade em determinado setor e adquirir vantagem competitiva, oferecendo produtos melhores e a preço premium.

Acredita-se que a inovação tecnológica adquirida pelas firmas integrantes dos consórcios de exportação favorece a performance exportadora de suas empresas. Partindo-se dessa consideração, foi formulada

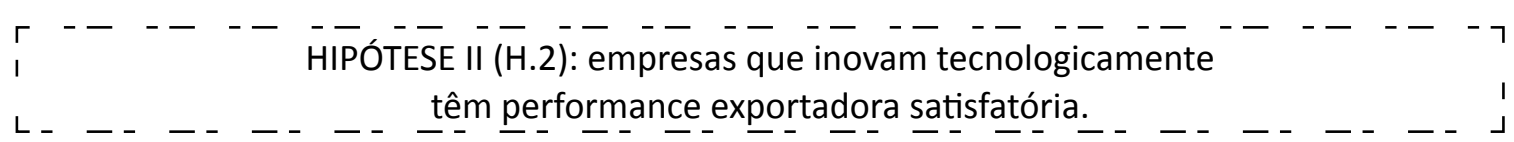

A inovação tecnológica em uma empresa pode ocorrer quando é realizada a criação (inovação radical) ou modificação de um produto (inovação incremental), englobando tanto os bens - tangíveis - quanto os serviços - intangíveis - Bessant e Tidd (2009, p.30) descrevem a inovação de produto como "mudança nas coisas que uma empresa oferece" e a exemplificam como um novo design de automóvel, novo pacote de seguro contra acidentes e novo sistema doméstico de entretenimento.

Todavia, a inovação em uma organização pode chegar a uma empresa sem estar vinculada a mudanças em processos e produtos, como ocorre por meio da inovação administrativa, definida pelo 
Manual de Oslo (2005) como "a implementação de um novo método organizacional nas práticas de negócios da empresa - rotinas e procedimentos -, na organização do seu local de trabalho - distribuição de responsabilidades e poder de decisão-, ou em suas relações externas" (OCDE, 2005, p. 61).

Enquanto a inovação tecnológica está relacionada ao produto e ao processo - atividades laborais básicas -, a inovação administrativa está envolvida com a estrutura da organização e o processo administrativo (DAMANPOUR, 1991). De acordo com Hall (1984), a estrutura da organização é a distribuição das pessoas que influenciam o desempenho da empresa; enquanto o processo administrativo é a ordem específica do trabalho dentro de um lugar, considerada a estrutura da ação (SILIPRANDI, 2010).

Um exemplo de inovação administrativa seriam os consórcios de exportação, que, como lembra Marques (2002), são agrupamentos de empresas que se relacionam para realização de um determinado objetivo, e, para isso, cria-se uma nova estrutura organizacional que responde pelo grupo. $\mathrm{O}$ autor explica que o consórcio de exportação funciona como uma cooperativa, na qual uma terceira empresa congrega grupos de empresas que fabricam e comercializam produtos similares, de forma que as decisões estratégicas referentes à exploração do mercado internacional sejam tomadas em conjunto. A terceira empresa criada é geralmente uma pessoa jurídica responsável por administrar o consórcio, que irá verificar os direitos e obrigações dos membros e procurar satisfazer os objetivos de todos.

Acredita-se que, através do consórcio de exportação, caracterizado como inovação administrativa, as empresas integrantes dos consórcios de exportação tenham acesso a inovações tecnológicas. Assim sendo, tem-se a terceira hipótese da pesquisa:

г -- HIPÓTESE- II - - - - - -- - - - - - - - I HIPOTESE III (H.3): o consórcio de exportação como inovação administrativa viabiliza L _ _ _ _ _ _ _ a aquisição de inovações tecnológicas às empresas. _ _ _ _ _ _ _ _ _ _ _ _ _ _ _ _

\section{MÉTODO}

A pesquisa propôs-se a verificar a atuação dos consórcios de exportação brasileiros em relação à cooperação dos membros (coerência e inovação), aquisição de inovações e performance exportadora. $O$ estudo está fundamentado sob três constructos: consórcio de exportação, inovação tecnológica e performance exportadora, relacionados com suas respectivas variáveis, que fornecerão as indicações para a obtenção dos dados. Dessa forma, deve-se verificar os aspectos referentes a consórcios de exportação, inovação e performance exportadora, apresentados abaixo.

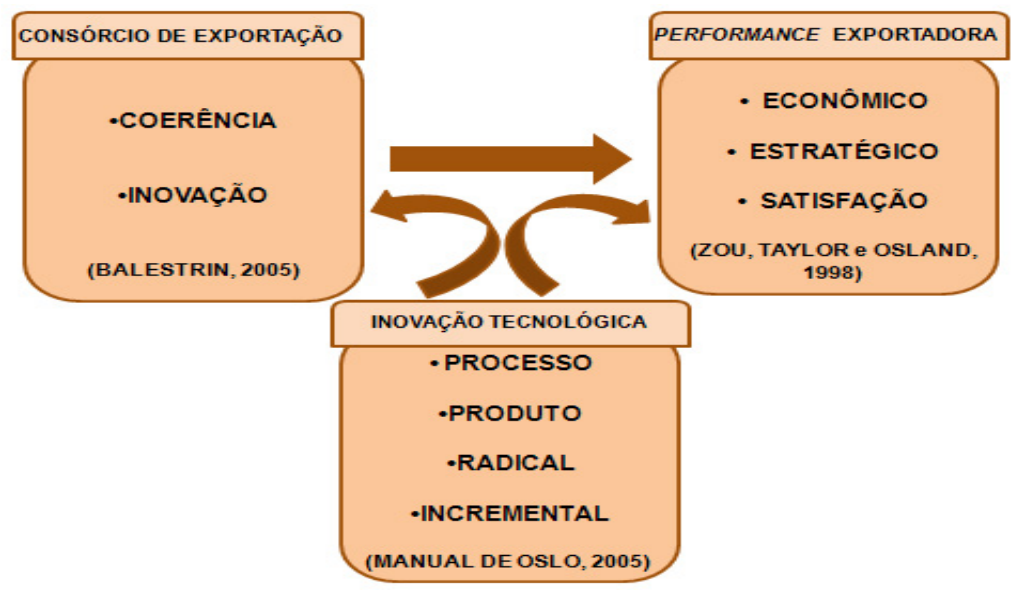

Figura 1- Modelo conceitual de pesquisa

Fonte: Elaborado pelos autores a partir de Zou, Taylor e Osland, 1998; Balestrin, 2005; Manual de Oslo, 2005. 
O estudo foi composto por uma pesquisa de abordagem quantitativa, em que se trabalha com um número amplo de respondentes, e o método envolve representações numéricas (GONÇALVES; MEIRELLES 2004). Tem-se um trabalho de natureza descritiva, verificando estatisticamente as questões correspondentes aos consórcios de exportação, inovação tecnológica e performance exportadora.

Utilizou-se o método survey de pesquisa para entender os comportamentos dos respondentes, empregando-se a avaliação, análise e descrição de uma população, baseado em uma amostra (BAKER, 2001). O questionário da pesquisa foi composto por questões com escalas Likert, tendo-se como base aspectos mensuráveis referentes ao consórcio de exportação, inovação e performance exportadora.

Tem-se como base que o consórcio de exportação corresponde a uma inovação administrativa, pelas justificativas já apresentadas ao longo do trabalho, relacionadas à estrutura de governança. O consórcio de exportação estaria relacionado com a obtenção de inovações tecnológicas e à performance exportadora.

Para a análise dessas considerações, foi realizada análise via estatística descritiva e, após, o coeficiente de Correlação de Pearson, de forma a identificar a relação entre as variáveis.

As empresas respondentes pertencem aos seguintes segmentos: aeroespacial (4 empresas), aviário ( 2 empresas), carne bovina ( 1 empresa), doces ( 2 empresas), equipamentos odontológicos (2 empresas), genética bovina ( 3 empresas), móveis (10 empresas), plantas (1 empresa), plásticos ( 3 empresas) e vinhos/espumantes ( 6 empresas), perfazendo uma amostra de 34 firmas estudadas, que foram analisadas por meio da estatística descritiva, como será apresentado a seguir.

\section{DISCUSSÃO E ANÁLISE DOS RESULTADOS}

De forma a analisar a atuação das empresas quanto a cooperação em consórcios de exportação, aquisição de inovações e performance exportadora para alicerçar as conclusões acerca das hipóteses formuladas, os dados foram analisados por meio da estatística descritiva, baseando-se na frequência percentual e média. Após, foi verificada a existência de correlação entre participação no consórcio de exportação e performance exportadora, na aquisição de inovações e performance exportadora, no consórcio de exportação e na aquisição de inovações.

\subsection{Participação no consórcio de exportação}

Pela ótica do consórcio de exportação como rede de cooperação (BALESTRIN, 2005), objetivou-se verificar o nível de cooperação (coerência) entre as empresas do consórcio e a rede como ato de inovação para melhoria dos processos empresariais.

Ainda que a teoria referente aos consórcios de exportação tenha como base sustentadora a formação de uma rede de cooperação empresarial (BALESTRIN, 2005), a maioria dos gestores $(44,1 \%)$ da área de negócios internacionais das empresas estudadas não apresentou ter opiniões concretas quanto a essa questão. Quando questionados acerca da existência de muitos projetos de cooperação entre as empresas integrantes, a maior parte dos respondentes $(32,4 \%)$ tem opinião negativa, ainda que não seja de extrema discordância.

Também, em quantidade idêntica, o número mais representativo das empresas $(32,4 \%)$ discorda, em grande parte, que há iniciativas conjuntas para a obtenção de inovações. Essa problemática, quanto à cooperação, pode estar relacionada com a existência de competição no 
mercado externo, entre as próprias empresas do consórcio, já que a maioria dos respondentes $(32,4 \%)$ concordou totalmente que há disputa entre os integrantes na arena internacional.

Soma-se, ainda, o fato que a maioria das empresas $(32,4 \%)$ compartilha interesses comuns no mercado exterior, o que pode causar motivos de desconfiança no acesso aos recursos estratégicos, conforme já mencionado por Negrini et al. (2007), e podendo corroborar o apontamento de Casarotto Filho e Pires (2007), ao quais dizem que não se têm, no Brasil, o mesmo espírito cooperador e a mesma cultura que se têm na Itália, país tido como exemplo na concretização de consórcios.

Embora os resultados, quanto ao nível de cooperação entre as empresas, levem a crer que há muita dificuldade quanto à prática da colaboração mútua entre empresas que visam a objetivos comuns, os resultados mostram que a maioria dos entrevistados $(32,4 \%)$ concorda que os membros do consórcio compartilham conhecimentos e auxiliam-se mutuamente. Relacionando essa consideração com as demais mencionadas supra, bem como a releitura de seus enunciados, entende-se que há projetos e intento de cooperação dentro do consórcio de exportação, mas que, poucas vezes, são concretizados.

Ainda em relação ao nível de cooperação entre as empresas, a maioria dos respondentes $(29,4 \%)$ concorda em grande parte que a cooperação entre os membros do consórcio vai muito além da participação em feiras internacionais, mostrando que a atuação consórcio de exportação não está reduzida apenas aos eventos internacionais.

A respeito da contribuição da rede em melhorias para a empresa, percebe-se que o consórcio de exportação atuou de forma benéfica na exploração do mercado internacional. A maioria das empresas analisadas $(29,4 \%)$ concorda que a atuação no mercado internacional se tornou mais fácil a partir do ingresso no consórcio (questão 11).

Nesse mesmo raciocínio, grande parte dos entrevistados $(29,4 \%)$ concorda que, com o ingresso no consórcio, a empresa alcançou novos mercados no exterior (questão 7) e observou (35,3\%) que, devido a participação no consórcio, foi possível a efetivação dos contratos internacionais. Corroborando o apontamento de Mtigwe (2006), uma rede de uma empresa tem grande valor como fonte de informação de mercado e conhecimento e impulsiona a obtenção de vantagens competitivas, sendo que uma firma isolada levaria um longo tempo para adquiri-las, e com um grande custo.

Conforme já exposto, Bessant e Tidd (2009) defendem que a inovação é de grande importância às empresas, sejam quais forem seus setores e tamanhos, e que esta é fortemente associada ao crescimento empresarial. Foi também apresentado que, de acordo com Vasconcellos (2004), muitos avanços são resultado da combinação de inovações tecnológicas e inovações administrativas, e que "não são raros os casos de inovações tecnológicas que não teriam ocorrido se não tivesse acontecido, prévia ou simultaneamente, alguma inovação administrativa" (VASCONCELLOS, 2004, p. 28).

De acordo com a maior parte das empresas da amostra $(29,4 \%)$, as inovações geradas foram facilitadas pela participação no consórcio de exportação (questão 15). No entanto, a maioria dos respondentes $(29,4 \%)$ não identifica que houve introdução de tecnologia nova ou significativamente melhorada, e criação de produtos que se diferem significativamente de todos os produtos previamente produzidos, ou que estas estão relacionadas ao consórcio de exportação.

Metade das empresas (50\%) concordou totalmente que foi o esforço individual o principal responsável pelas inovações adquiridas, o que correspondeu a uma média de 4,0588, a segunda maior do bloco de questões pesquisadas. Dessa forma, é possível entender que a empresa deve ter uma atitude empreendedora e proativa, além de recursos cabíveis (humanos e 
financeiros) para trazer inovação ao seu empreendimento, sendo que o consórcio de exportação pode ser um meio de acesso à aquisição e ao conhecimento dessa busca.

Nesse caminho, retomam-se os serviços dos consórcios de exportação, apontados por Casarotto Filho e Pires (2001): divulgação de informações do setor de atuação da empresa, que podem representar futuras oportunidades técnicas; pesquisas de mercado, auxiliando no delineamento das possibilidades de inserção do produto; difusão de informações sobre o ambiente de ação das empresas; campanhas de marketing; projetos comuns de financiamento; consultorias acerca de problemas comuns do setor e promoção das empresas no território, sediando convenções e encontros empresariais do ramo participação conjunta em feiras nacionais e internacionais. As feiras internacionais são consideradas a melhor maneira de realizar contatos com possíveis compradores e conhecer os produtos que as empresas concorrentes do mundo oferecem aos clientes.

Por envolverem grande quantia financeira (passagens, estadias, pagamento de stands para exposição), as feiras internacionais acabam se tornando uma oportunidade distante para as empresas que possuem poucos recursos e atuam sozinhas no mercado internacional. Corroborando esse fato, grande parte da amostra $(52,9 \%)$ concorda totalmente que pertencer ao consórcio de exportação auxiliou na redução dos custos nas feiras internacionais, correspondendo à maior média do bloco de questões.

\subsection{INOVAÇÃO}

Conforme explicitado no desenvolvimento da presente pesquisa, a inovação é considerada como um grande diferencial competitivo das empresas nos estudos internacionais. Como esses mercados são caracterizados por uma maior pressão competitiva que o mercado nacional, a inovação torna-se inevitável para sobrevivência das empresas (FILIPESCU, 2007).

Como o mercado internacional é considerado exigente, a metade dos respondentes (50\%) concorda totalmente que busca se adequar aos padrões internacionais de produto, o que corresponde à maior média do bloco de questões, sendo que $32,8 \%$ concordam, em grande parte, na busca por essa adequação. Da mesma forma, a maioria $(47,1 \%)$ busca adequação aos padrões internacionais de maquinaria, e $35,3 \%$ já se encontram próximas destes, mostrando que as empresas brasileiras dos consórcios buscam aprimoramento em Inovação TPP (Inovação Tecnológica em Produto e Processo).

O panorama referente à inovação nas empresas estudadas é satisfatório, pois 44,1 \% consideram-se praticamente dentro dos padrões internacionais, e $35,3 \%$ já se consideram inteiramente nos padrões mundiais. A maior parte das empresas $(32,4 \%)$, inclusive, concorda totalmente que produziu muitas inovações em produto, nos últimos três anos, e 35,3\% verificam que realizaram mudanças técnicas nos últimos três anos.

Como já mencionado, Bessant e Tidd (2009) lembram que preocupações sociais e políticas sobre o meio ambiente e a sustentabilidade apresentam uma influência fundamental [...] sobre o rumo da inovação. Observando essa tendência, a maior parte das empresas $(32,4 \%)$ afirma que, nos últimos três anos, moldou-se às questões ecológicas de obtenção de matéria-prima.

Quanto à inovação incremental e radical, 52,9\% realizam ajustes/melhorias em produtos já existentes, e 58,8\% criam novos produtos. Assim, verifica-se que a maior parte das empresas realiza algum tipo de inovação em produtos, e tais inovações são, em pequeno grau, de novidade (incremental) e melhorias significativas (radical).

A maioria das firmas $(47,1 \%)$ acredita que as feiras internacionais são uma boa oportunidade 
de verificar se os produtos da empresa estão em conformidade com o mercado internacional, e 38, $2 \%$ acredita, em parte, que a participação nas feiras é um bom caminho na aquisição da inovação.

Outro meio na aquisição de inovação às empresas é o de Chesbrought (2003), de Open Innovation - Inovação Aberta -, em que as empresas formam parcerias com universidades e institutos de pesquisa, compartilhando competências e dividindo o conhecimento. Essa é uma tendência usual em países desenvolvidos, e acredita-se que esse fato se estenderá ao Brasil, de forma que $26,5 \%$ das empresas já usufruíram dos benefícios de alguma pesquisa científica.

\subsection{Performance exportadora}

O constructo referente à performance exportadora visou a buscar as constatações dos gestores a respeito do desempenho das suas empresas no mercado internacional, e chamou atenção o número de respostas que discordavam totalmente das afirmações, mostrando insatisfação quanto ao desempenho.

De acordo com a maioria das respostas, as empresas não têm alcançado resultados benéficos quanto ao desempenho financeiro no mercado exterior (35,5\% não geraram alto volume de vendas, e 38,2\% não alcançaram rápido crescimento), estratégico (29,4\% não melhoraram a competitividade internacional, e $32,4 \%$ não aumentaram a participação no mercado global) e satisfatório (32,4\% das empresas não têm desempenho internacional satisfatório, e 29,4\% dos empreendimentos não alcançaram integralmente as expectativas). Aspectos referentes à lucratividade, ao fortalecimento da posição estratégica e ao sucesso do empreendimento exportador não têm considerações bem definidas pelos respondentes, que não mostraram respostas extremas.

A partir das respostas, verifica-se que, embora as empresas tenham optado pela participação no consórcio de exportação para facilitar ou ampliar a exploração do mercado global e a maioria realize inovações em processo e produto, adequando-se aos padrões internacionais de exigência, a performance exportadora ainda é insatisfatória.

\subsection{Relação entre participação no consórcio exportador e performance exportadora}

Dando continuidade à investigação dos objetivos da pesquisa, foi verificado se existe relação positiva entre a participação no consórcio de exportador e a performance exportadora resultante, utilizando-se, como ferramenta de apoio, o software SPSS17.

Como lembra Lira (2004, p. 43), "em estudos que envolvem duas ou mais variáveis, é comum o interesse em conhecer o relacionamento entre elas, além das estatísticas descritivas normalmente calculadas" e, para verificar se a teoria corresponde à realidade das empresas do estudo, optou-se pela realização da correlação do Coeficiente de Pearson.

Murteira (1993) aponta que esta correlação significa que a intensidade de um fenômeno é acompanhada pela intensidade do outro. De acordo com Pestana e Gageiro (2003), quando $p<0,05$, significa que existe relação entre as variáveis, e a intensidade desta é verificada da seguinte forma, observando o coeficiente de correlação ( $r$ ): de 0,01 a 0,2: relação muito baixa; de 0,2 a 0,39: relação baixa; de 0,4 a 0,69: relação moderada; de 0,7 a 0,89: relação alta; de 0,9 e 1: relação muito alta.

Relacionando os dados referentes a consórcios de exportação e performance exportadora, tem-se:

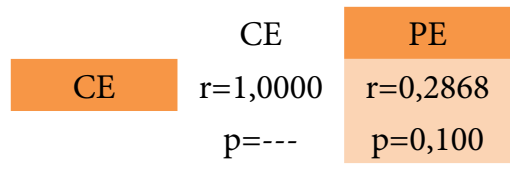


Como, para existir correlação entre as variáveis, deve-se ter $p<0,05$, descarta-se a relação entre consórcios de exportação e performance exportadora para as empresas brasileiras. Assim, para a maioria das empresas, o fato de participar de um consórcio de exportação, no momento, não facilita o desempenho exportador.

\subsection{Relação entre aquisição de inovações e performance exportadora}

Dando continuidade ao uso do coeficiente de correlação de Pearson como forma de verificar associação entre as variáveis estudadas, foi verificado se há relação entre aquisições de inovação pela empresa e a performance exportadora.

Retomando alguns pontos da literatura já apresentados neste trabalho, tem-se a associação entre inovação e crescimento empresarial, na qual Bessant e Tidd (2009) afirmaram que as empresas que não inovam correm o risco de serem superadas por outras que o façam, sendo, então, uma questão de sobrevivência a qualquer firma a aquisição da inovação.

Igualmente, Arbix (2005) verificou que a inovação tecnológica está fortemente associada com a internacionalização da empresa e constatou que as firmas que inovam seus produtos e processos são mais produtivas, têm maiores parcelas de mercado, retorno maior de investimento, e empregam pessoal mais qualificado, valorizando o capital humano e o conteúdo tecnológico obtido por meio da aprendizagem na empresa.

Os dados coletados na pesquisa, referentes à inovação e performance exportadora quando trabalhadas no SPSS, resultaram em

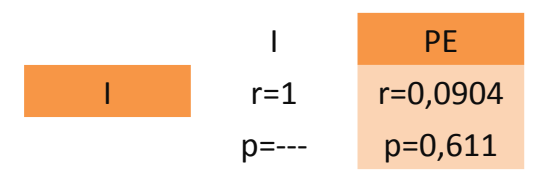

Como é necessário ter $p<0,05$ para que exista correlação entre as variáveis, constatase que, nas empresas da amostra, a inovação e a performance exportadora não estão associadas.

Corroborando essa falta de relação, lembra-se de que, nos dados obtidos na análise descritiva, enquanto os apontamentos acerca da performance exportadora evidenciaram uma grande distância entre a realidade da empresa e desempenho considerado satisfatório, as respostas relativas à inovação mostraram proximidade entre realidade e padrão.

\subsection{Relação entre participação no consórcio de exportação e aquisição de inovações}

De acordo com a literatura utilizada no desenvolvimento da pesquisa, tem-se a consideração de Vasconcellos (2004), que acredita que muitos avanços na empresa são resultado da combinação de inovações tecnológicas e inovações administrativas, e muitas inovações tecnológicas não teriam ocorrido se não tivesse acontecido, prévia ou simultaneamente, alguma inovação administrativa. Assim, tem-se um apoio para que o consórcio de exportação (inovação administrativa) favoreça a aquisição de inovações tecnológicas.

Recorda-se que Verschoore (2006) defendeu que a combinação de recursos necessários à inovação pode ser viabilizada eficientemente com a formação de uma rede de cooperação e constitui um benefício apropriado pelas empresas participantes, porém inatingível para as empresas externas a ela.

Para contestar ou apoiar a existência dessa vinculação, mais uma vez, foi realizada a verificação do coeficiente de correlação de Pearson, desta vez, com as variáveis consórcio de exportação e inovação. 
Teve-se como resultado:

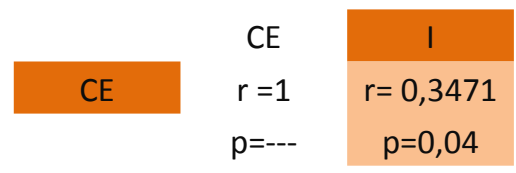

Sendo $p=0,044$ e $r=0,3471$, nota-se a existência de correlação entre as variáveis, já que, neste caso, $p<0,05$. Constata-se, assim, que é possível apoiar a ligação entre consórcio de exportação e aquisição de inovações tecnológicas nas empresas da amostra. Também, podese dizer que há associação positiva entre as variáveis, e, então, o aumento de uma variável aumentaria a outra.

Pestana e Gageiro (2003) lembram que o coeficiente de correlação de Pearson é uma medida linear entre variáveis quantitativas e varia entre -1 e 1 , sendo que, quanto mais próximo estiver dos extremos. maior é a associação linear. Tendo $r=0,3471$, verifica-se que a associação linear é baixa, pois, como já explicitado anteriormente, esta é a intensidade se o coeficiente de correlação for de 0,2 a 0,39.

Assim, embora exista ligação entre consórcio de exportação e aquisição de inovações tecnológicas, esta não tem grande intensidade. Entende-se, então, que o consórcio pode viabilizar as ações inovadoras às empresas, mas não é o principal meio existente.

As evidências de que existe associação entre consórcios de exportação e aquisição de inovações, mas que esta ligação é baixa, são também corroboradas ao verificar a estatística descritiva apresentada, em que $29,4 \%$ das empresas concordam que as inovações geradas pela empresa foram facilitadas com a participação no consórcio; no entanto $50 \%$ afirmam que o esforço individual da firma foi o maior responsável pelas inovações adquiridas.

\subsection{Validade das hipóteses}

Após as análises advindas da estatística descritiva e correlação de Pearson, foram alimentadas as bases empíricas capazes de corroborar ou refutar os três pressupostos básicos balizadores da pesquisa.

A estatística descritiva mostrou que as empresas do consórcio acreditam que a participação na rede facilitou a aquisição de inovações, possivelmente devido às atribuições do consórcio, que organiza consultorias, facilita e organiza visitas às feiras internacionais. No entanto, se a empresa não buscasse a inovação de forma proativa, esta provavelmente não ocorreria.

Ratificando essas considerações, através da correlação de Pearson, verificou-se que, por existir $p=0,044$ e $r=0,3471$, há relação entre as variáveis, mas a intensidade dela é baixa.

Assim sendo, tem-se:

H.1: Empresas que integram algum consórcio de exportação têm performance exportadora satisfatória HIPÓTESE REFUTADA

H.2: Empresas que inovam têm performance exportadora satisfatória. HIPÓTESE REFUTADA

H.3: O consórcio de exportação, como inovação administrativa, viabiliza a aquisição de inovações tecnológicas às empresas. HIPÓTESE CORROBORADA 
Cumpre-se, assim, o objetivo geral da pesquisa, no qual a proposta era verificar a atuação dos consórcios de exportação brasileiros em relação à cooperação, aquisição de inovações e performance exportadora, apresentando as características das firmas, descrevendo e analisando, por meios estatísticos, a atuação das empresas quanto à participação no consórcio de exportação, aquisição de inovações e performance exportadora, além de verificar a relação entre esses três constructos.

\section{CONSIDERAÇÕES FINAIS}

A presente pesquisa objetivou verificar a atuação dos consórcios de exportação brasileiros em relação à cooperação, à aquisição de inovações tecnológicas e aos impactos na performance exportadora das empresas integrantes, descrevendo e analisando resultados coletados e verificando a relação entre consórcio de exportação, inovação e performance exportadora.

Por meio da estatística descritiva, foi analisada a atuação das empresas acerca da participação no consórcio de exportação, aquisição de inovações e performance exportadora, descrevendo o comportamento das firmas em relação a cada constructo através da maior frequência percentual encontrada nas questões.

Com referência à participação no consórcio de exportação, destaca-se como a maior frequência percentual do bloco, com 52,9\%, a concordância em relação a redução dos custos nas feiras internacionais. A segunda maior representatividade de respostas, com $50 \%$, foi que o esforço individual é o maior responsável pela aquisição de inovações, e não a participação no consórcio.

Em relação à aquisição de inovações tecnológicas, 58,8\% das empresas dizem realizar inovações radicais, e 52,9\% realizam inovações incrementais (essas informações não fazem parte da mesma questão). Metade das empresas afirma que seus produtos estão nos padrões internacionais, sendo que $47,1 \%$ acreditam que as feiras internacionais são os locais ideais para verificar o nível desses padrões.

A performance exportadora tem sido um fator crítico para as empresas que desejam a consolidação no mercado internacional, já que a maioria das respostas revela grande distância entre a realidade da empresa e a performance satisfatória. Verificou-se baixo volume de vendas e crescimento lento no mercado internacional como questões de maior média no bloco.

Retomando-se as três hipóteses levantadas acerca do referencial teórico da pesquisa, sendo estas: "empresas que integram algum consórcio de exportação têm performance exportadora satisfatória"; "empresas que inovam tecnologicamente têm performance satisfatória"; e "o consórcio de exportação, como inovação administrativa, viabiliza a aquisição de inovações tecnológicas às empresas", verifica-se que a mesmas podem ser refutadas. Por meio da amostra do estudo, constatou-se a baixa cooperação entre as empresas, percebida pelo fato de que a busca pela inovação é um caminho individual, e, embora muitas empresas estejam inovando tecnologicamente em produtos e processos, o desempenho das atividades internacionais ainda é baixo.

Ainda que as empresas da amostra tenham apresentado bons resultados referentes à inovação, revelando que zelam por práticas inovadoras a performance exportadora é bastante baixa, provavelmente devido às questões que ainda assombram os gestores das empresas, relacionadas às dificuldades internas e externas à exportação Nesse pensamento, mesmo que algumas empresas já estejam preparadas para a competição internacional, esses entraves acabam se sobrepondo à performance.

As análises mostram que as potencialidades dos consórcios de exportação previstas 
na literatura não estão sendo utilizadas integralmente, acarretando, assim, a baixa performance exportadora nos eixos financeiro, econômico e satisfatório. Também, durante a fase da coleta de dados, constatou-se que a maioria dos consórcios começou com um número maior de integrantes que, ao passar do tempo, abandonaram a participação, o que significa insatisfação quanto aos resultados provenientes da parceria.

Foi percebido baixo trabalho cooperativo entre as empresas, tais como projetos de colaboração e iniciativas conjuntas para obtenção de inovações como as parcerias com universidades, o que, de forma contrária, poderia favorecer o desempenho das empresas no exterior.

A intensificação da cooperação entre empresas do mesmo segmento em busca de um objetivo comum não é uma meta utópica, pois há o exemplo italiano de consórcios de exportação e demais redes de empresas, que, através de esforços conjuntos, atingem uma performance exportadora bastante satisfatória. De acordo com Minervini (2008), há, na Itália, cerca de 380 grupos de consórcio, cada um contendo em média 50 empresas, que são responsáveis por $12 \%$ da receita de exportação (no Brasil, esse índice corresponde a 1,2\%) e raramente desistem da parceria.

Ainda, os dados empíricos evidenciam que as empresas brasileiras focam em atividades de curto prazo, visando unicamente à inserção no mercado internacional, e não na aprendizagem da maturidade na atuação no exterior, na fortificação da marca do consórcio e nas ações de integração entre os membros, que visem à permanência da associação. Diferentemente, em países onde os consórcios de exportação figuram como impulsionadores de exportações e aquisição de inovações, as empresas integrantes focam as atividades que não vislumbram apenas o curto prazo.

Percebendo a criação de redes de cooperação nos mais diversos contextos da sociedade como tendência do mundo atual, acredita-se que seja importante a realização de estudos futuros mais aprimorados, os quais busquem compreender os motivos que fazem com que os consórcios de exportação não rendam aquilo que poderiam, por meio de pesquisas que se estendam aos níveis de cooperação, gestão e apoio dos órgãos de incentivo.

Teve-se como limitação da pesquisa o tamanho da amostra trabalhada, composta por 34 respondentes, o que impossibilitou a realização de outros tipos de análise, como a multivariada, para determinar a dependência ou interdependência dentro da pesquisa.

De qualquer forma, acredita-se que a pesquisa realizada trouxe contribuições teóricas às ciências administrativas, já que existem lacunas no âmbito de consórcios de exportação, inovação e performance exportadora. Espera-se que as contribuições teóricas da pesquisa possam ser expandidas à prática nas empresas, de forma a colaborar com a gestão dos consórcios de exportação e possibilitar que possam ser visualizados os aspectos que carecem maior atenção para que os benefícios que são possíveis com a integração sejam alcançados. 


\section{REFERÊNCIAS}

ANDERSSON, S. The Internationalization of the firm from an entrepreneurial perspective. International Studies of Management and Organizations, 2000.

ARBIX, G. Inovações, padrões tecnológicos e desempenho das firmas industriais brasileiras. Anais do XVII Fórum Nacional China e Índia como desafio e exemplo e a reação do Brasil... para cima, Rio de Janeiro, 2005.

BAKER, M. J. Selecting a Research Methodology. The Marketing Review, Westburn

Publishers Ltda, v. 1, p. 373-397, 2001

BALESTRIN, A. A dinâmica da complementaridade de conhecimentos no contexto das redes interorganizacionais. Tese (Doutorado). Universidade Federal do Rio Grande do Sul, Porto Alegre, 2005.

BESSANT, J.; TIDD, J. Inovação e empreendedorismo. Porto Alegre: Bookman, 2009.

BRANCO, P. L.; MACHADO, M. A. Consórcio de exportação: um estudo comparativo entre o modelo brasileiro APEX e o modelo FEDEREXPORT. Revista de Práticas Administrativas, v.3, n.1, 2004.

CASSAROTO FILHO, N.; PIRES, L. H. Redes de pequenas e médias empresas e desenvolvimento local. São Paulo: Atlas, 2001.

CASTELLS, M. A sociedade em rede. São Paulo: Paz e Terra, 1995.

CHESBROUGH, H.W. The era of open innovation. MIT Sloan Management Review, spring, 2003.

CHURCHILL JR., G.A.; PETER, J.P. Marketing: criando valor para os clientes. São Paulo: Saraiva, 2000.

DAMANPOUR, F. Organizational innovation: a meta-analysis of effects of determinants and moderators. Academy of Management Journal, v. 34, n.3, 1991.

FILIPESCU, D.A. Innovation and internationalization. a focus on exporting firms. Tese (Doutorado). Universitat Autonòma de Barcelona, 2007.

FISCHER, B.B. Relação entre estratégia de entrada em mercados estrangeiros e performance exportadora resultante em empresas brasileiras. In: Anais do XXX Encontro da ANPAD, Salvador, 2006.

GARRIDO, I.L. A relação entre orientação para o mercado externo, estratégias de internacionalização e performance exportadora. Tese (doutoramento). Universidade Federal do Rio Grande do Sul, Porto Alegre, 2007.

GONÇALVES, C.A.; MEIRELLES, A.M. Projetos e relatórios de pesquisa em administração. São Paulo: Atlas, 2004.

JOHANSON, J.; WIEDERSHEIM-PAUL, F. The internationalization of the firm. Journal of Management Studies, v.12, 1975.

JOHANSON,J ; VAHLNE, J .E. The mechanism os internatiolisation. International Marketing Review, 1990.

KATSIKEAS, C.S.; PIERCY, N.F.; LOANNIDIS, C. 1996. Determinants of export performance in a European context. European Journal of Marketing, n. 30, v.6, 1996.

KUAZAQUI, E. Marketing internacional: como conquistar negócios em mercados internacionais. São Paulo: Makron Books, 1999.

KUAZAQUI, E.; LISBOA, T.C. Estratégias de entrada e operações em mercados internacionais:China. Anais do èmme colloque de I'IFBAE, grenoble, 18 et 19 mai, 2009.

NEELY, A; GREGORY, M; PLATTS, K. Performance measurement system design: a literature review and research agenda. International Journal of Operations \& Production Management, 
v. 15, n. 4, 1995.

PORTER, M. E. A vantagem competitiva das nações. Rio de Janeiro: Campus, 1989.

PORTO, E. C. Os consórcios de exportação como instrumentos facilitadores de estratégias cooperativas para micro, pequenas e médias empresas. Revista de Práticas Administrativas, v.2, n.6, 2006.

ROCHA, A.; SILVA, J. F.; CARNEIRO, J. Expansão internacional das empresas brasileiras revisão e síntese. In: FLEURY, A.; FLEURY, M.T.L. Internacionalização e os países emergentes. São Paulo: Atlas, 2007.

MACHADO, M.A. $O$ envolvimento exportador e a performance exportadora: uma revisão analítica em busca de uma tipologia explanatória para a exportação. Disponível em <http:// www.unieducar.org.br.../O\%20Envolvimento\%20Exportador\%20e\%20a\%20Performance\% >. Acesso em: 15.dez.2010.

MAIS, I.; CARVALHO, L.C.; AMAL, M.; HOFFMANN, M.G. Importância das redes nos processos de inovação e internacionalização de empresas de base tecnológica. RAI - Revista de Administração e Inovação, São Paulo, v. 7, n. 1, p. 41-61, jan./mar . 2010.

NICKELS, W.G.; WOOD, M.B. Marketing: relacionamentos, qualidade, valor. Rio de Janeiro: LTC, 1999.

ORGANIZAÇÃO PARA COOPERAÇÃO ECONÔMICA E DESENVOLVIMENTO. Manual de Oslo: proposta de diretrizes para coleta e interpretação de dados sobre inovação tecnológica. FINEP - Financiadora de Estudos e Projetos, 2004.

OSLAND, G. E.; TAYLOR, C. R.; ZOU, S. Selecting international modes of entry and expansion. Marketing Intelligence \& Planning, v. 19, n. 3, p. 153-161, 1998

SCHERER, F. L. ; GOMES, C. M. . Relações entre Perfil Empresarial, Estratégia e Performance em Mercados. In: XI SEMEAD, 2008, São Paulo. Anais do XI SEMEAD, 2008.

SILIPRANDI, E. M. Modelo de relacionamento e avaliação do processo de inovação na indústria de softwares. Tese (Doutorado). Universidade Federal do Rio Grande do Sul, Porto Alegre, 2010.

STAL, E. Internacionalização de empresas brasileiras e o papel da inovação na construção de vantagens competitivas. RAl- Revista de Administração e Inovação, São Paulo, v. 7, n. 3, p. 118-147, jul./set. 2010.

VASCONCELLOS, M.A. Introdução. In: BARBIE$\mathrm{RI}$, José Carlos et al. Organizações inovadoras: estudos e casos brasileiros. São Paulo: FGV Editora, 2004. 